$$
\text { Special Article }
$$

\title{
PSYCHOLOGICAL SEQUELAE OF THE SEPTEMBER 11 TERRORIST ATTACKS IN NEW YORK CITY
}

\author{
Sandro Galea, M.D., M.P.H., Jennifer Ahern, M.P.H., Heidi Resnick, Ph.D., Dean Kilpatrick, Ph.D., \\ Michael Bucuvalas, Ph.D., Joel Gold, M.D., and David Vlahov, Ph.D.
}

\begin{abstract}
Background The scope of the terrorist attacks of September 11, 2001, was unprecedented in the United States. We assessed the prevalence and correlates of acute post-traumatic stress disorder (PTSD) and depression among residents of Manhattan five to eight weeks after the attacks.
\end{abstract}

Methods We used random-digit dialing to contact a representative sample of adults living south of 110th Street in Manhattan. Participants were asked about demographic characteristics, exposure to the events of September 11, and psychological symptoms after the attacks.

Results Among 1008 adults interviewed, 7.5 percent reported symptoms consistent with a diagnosis of current PTSD related to the attacks, and 9.7 percent reported symptoms consistent with current depression (with "current" defined as occurring within the previous 30 days). Among respondents who lived south of Canal Street (i.e., near the World Trade Center), the prevalence of PTSD was 20.0 percent. Predictors of PTSD in a multivariate model were Hispanic ethnicity, two or more prior stressors, a panic attack during or shortly after the events, residence south of Canal Street, and loss of possessions due to the events. Predictors of depression were Hispanic ethnicity, two or more prior stressors, a panic attack, a low level of social support, the death of a friend or relative during the attacks, and loss of a job due to the attacks.

Conclusions There was a substantial burden of acute PTSD and depression in Manhattan after the September 11 attacks. Experiences involving exposure to the attacks were predictors of current PTSD, and losses as a result of the events were predictors of current depression. In the aftermath of terrorist attacks, there may be substantial psychological morbidity in the population. (N Engl J Med 2002;346:982-7.) Copyright (c) 2002 Massachusetts Medical Society. $\longrightarrow$ HE attacks of September 11, 2001, represented the largest act of terrorism in U.S. history. Approximately 3000 people were killed in New York City alone. ${ }^{1}$ Severe lasting psychological effects are generally seen after disasters causing extensive loss of life, property damage, and widespread financial strain and after disasters that are intentionally caused. ${ }^{2}$ These elements were all present in the September 11 attacks, suggesting that the psychological sequelae in New York City are substantial and will be long-lasting.

We conducted a study to determine the prevalence of psychopathologic disorders in Manhattan after September 11 and to identify predictors of these conditions. We focused on post-traumatic stress disorder (PTSD) and depression, the two most commonly studied psychological sequelae of trauma and disasters. $^{3-5}$

\section{METHODS}

\section{Data Collection and Sample}

Data were collected through telephone interviews with a random sample of Manhattan residents between October 16 and November 15, 2001. The institutional review board of the New York Academy of Medicine approved the study, and oral informed consent was obtained from the study subjects.

The sampling frame consisted of adults living in households with telephones in Manhattan. We restricted the sample to households south of 110th Street, a demographically homogeneous area and the part of Manhattan that is closest to the World Trade Center (Fig. 1). Using random-digit dialing, we screened households for geographic eligibility, and an adult in each household was randomly selected to be interviewed (whoever had the most recent birthday was selected). We made up to 10 attempts to contact an adult at each number. The overall cooperation rate for the survey was 64.3 percent.

\section{Study Instruments}

Respondents were asked questions from a structured questionnaire in English or Spanish. We asked questions about demograph-

From the Center for Urban Epidemiologic Studies, New York Academy of Medicine, New York (S.G., J.A., J.G., D.V.); the Department of Epidemiology, Columbia University Mailman School of Public Health, New York (S.G., D.V.); the National Crime Victims' Research and Treatment Center, Medical University of South Carolina, Charleston (H.R., D.K.); Schulman, Ronca, and Bucuvalas, New York (M.B.); and Bellevue Hospital Center, New York (J.G.). Address reprint requests to Dr. Galea at the Center for Urban Epidemiologic Studies, Rm. 556, New York Academy of Medicine, 1216 Fifth Ave., New York, NY 10029-5283, or at sgalea@nyam.org. 


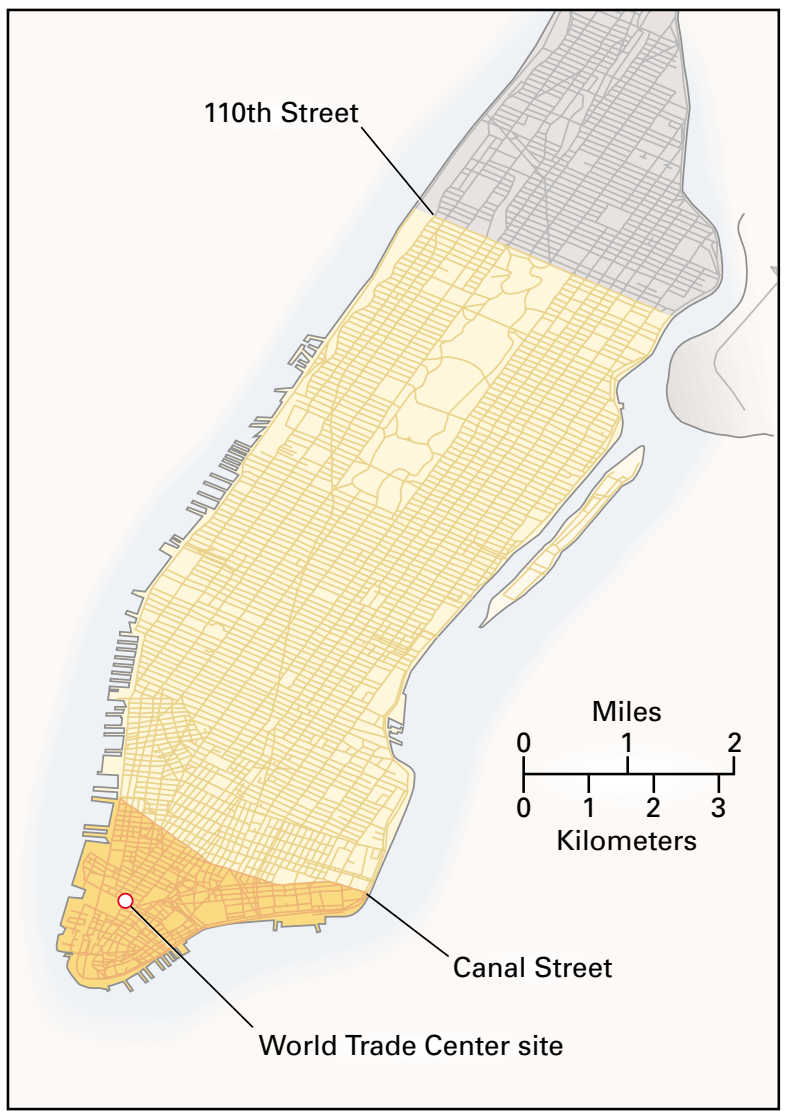

Figure 1. Sampling Frame in Relation to the Site of the World Trade Center.

The sampling frame includes the area between 110th Street and Canal Street (yellow), and the area south of Canal Street (orange).

ic characteristics, where the respondent was living before September 11 , and the respondent's location during the attacks. For the analyses, total social support was categorized as low, medium, or high. We asked about three aspects of social support - emotional (i.e., "someone to love you and make you feel wanted"), instrumental (i.e., "someone to help you if you were confined to bed"), and appraisal (i.e., "someone to give you good advice in a crisis") — in the six months before September $11 .{ }^{6}$ We also asked whether the respondent had experienced any of eight stressful events (e.g., the death of a spouse) in the previous year.

Respondents were asked whether they had directly witnessed the attacks, had feared they would die during the attacks, had friends or relatives who were killed during the attacks, had been displaced from home, had been involved in the rescue effort, or had lost a job or possessions because of the attacks. Documentation of a panic attack was based on a modified version of the National Institute of Mental Health Diagnostic Interview Schedule; the diagnosis required the development of at least four characteristic symptoms during or soon after the attacks.

PTSD was assessed with the use of the PTSD questionnaire from the National Women's Study, which is a modified version of the Diagnostic Interview Schedule for PTSD. For the diagnosis of current PTSD, this instrument has a coefficient of 0.71 for agreement with clinician-administered structured clinical interviews, and it uses a non-event-specific approach to the assessment of PTSD symptoms. ${ }^{5}$ Current PTSD was defined as the presence of at least one recurrent symptom (e.g., intrusive memories or distressing dreams), three avoidance symptoms (e.g., efforts to avoid thoughts associated with the trauma or loss of interest in activities associated with it), and two symptoms of hyperarousal (e.g., difficulty falling asleep or concentrating). All symptoms must have persisted for 2 weeks or longer and must have been present within the previous 30 days to qualify as symptoms of current PTSD. In addition, for symptoms that involved specific content (e.g., memories or thoughts), we asked about the content; these symptoms had to be related to the September 11 attacks to qualify as symptoms of current PTSD. We used a modified, validated version of the Structured Clinical Interview in the Diagnostic and Statistical Manual of Mental Disorders, fourth edition, for a major depressive episode to determine the presence of depression within the previous 30 days. $^{7}$

\section{Statistical Analysis}

We calculated both the overall prevalences of current PTSD and depression and the prevalences according to covariates of interest. Two-tailed chi-square tests were used to identify associations between covariates and either PTSD or depression. Multiple logistic regression was used to examine predictors separately for PTSD and depression. Covariates were considered in a multivariate regression model in which bivariate chi-square $\mathrm{P}$ values were less than 0.1 . Differences in $\log$ likelihood $(\mathrm{P}<0.05)$ were used to determine whether variables would be retained in subsequent models. We tested for interactions between key predictor variables in the final models. Analyses were weighted to compensate for potential bias due to the number of adults in a household and the number of telephones. We used SUDAAN software to adjust all analyses for weighting. ${ }^{8}$

\section{RESULTS}

\section{Sample}

Of the 1008 adults surveyed, 20 were excluded from the analysis because of missing weight variables (i.e., the number of adults or the number of telephones in the household). Overall, 52.0 percent of the respondents were women, and 71.6 percent were white; the mean $( \pm S D)$ age was $42 \pm 15$ years. Age, sex, race or ethnic group, and residence distributions in our sample were similar to estimates obtained from the 2000 U.S. Census for our sampling frame. ${ }^{9}$ On September 11, 5.2 percent of the respondents lived south of Canal Street.

\section{Prevalence of PTSD and Depression}

The prevalence of PTSD was 7.5 percent (95 percent confidence interval, 5.7 to 9.3 percent), and the prevalence of depression was 9.7 percent $(95$ percent confidence interval, 7.3 to 11.3 percent). Overall, 13.6 percent of the respondents reported symptoms that met the criteria for either PTSD or depression, and 3.7 percent reported symptoms that met the criteria for both disorders.

\section{Bivariate Analyses}

Table 1 shows the results of bivariate analyses. The covariates associated with whether the respondent 
Table 1. Bivariate Associations between Characteristics of the Respondents and Current Post-Traumatic Stress Disorder (PTSD) or Depression.*

\begin{tabular}{|c|c|c|c|c|c|}
\hline VARIABLE & $\begin{array}{c}\text { No. OF } \\
\text { RESPONDENTSt }\end{array}$ & PTSD & $\underset{\text { VALUE }}{P}$ & Depression & $\begin{array}{c}P \\
\text { VALUEF }\end{array}$ \\
\hline & & $\%$ & & $\%$ & \\
\hline Total & 988 & 7.5 & & 9.7 & \\
\hline Sex & & & 0.005 & & 0.03 \\
\hline Male & 469 & 4.8 & & 7.3 & \\
\hline Female & 519 & 9.9 & & 12.0 & \\
\hline Race or ethnic group & & & 0.07 & & 0.03 \\
\hline White & 702 & 6.5 & & 7.4 & \\
\hline Black & 49 & 9.3 & & 11.9 & \\
\hline Asian & 67 & 3.2 & & 5.8 & \\
\hline Hispanic & 114 & 13.8 & & 20.4 & \\
\hline Other & 17 & 19.1 & & 19.1 & \\
\hline Annual household income & & & 0.10 & & 0.006 \\
\hline$\geqslant \$ 100,000$ & 308 & 4.9 & & 5.9 & \\
\hline$\$ 75,000-\$ 99,999$ & 96 & 10.2 & & 9.1 & \\
\hline$\$ 40,000-\$ 74,999$ & 178 & 10.0 & & 15.3 & \\
\hline$\$ 20,000-\$ 39,999$ & 135 & 12.5 & & 16.5 & \\
\hline$<\$ 20,000$ & 93 & 8.5 & & 14.4 & \\
\hline Education & & & 0.33 & & 0.007 \\
\hline Graduate work & 313 & 5.6 & & 7.2 & \\
\hline College degree & 441 & 8.2 & & 7.5 & \\
\hline$<$ College degree & 229 & 8.5 & & 16.8 & \\
\hline Residence before September 11 & & & 0.04 & & 0.26 \\
\hline Between 110th St. and Canal St. & 938 & 6.8 & & 9.3 & \\
\hline South of Canal St. & 50 & 20.0 & & 16.8 & \\
\hline Social support in previous 6 mo & & & 0.01 & & $<0.001$ \\
\hline High & 313 & 4.4 & & 5.6 & \\
\hline Medium & 267 & 8.7 & & 7.3 & \\
\hline Low & 358 & 10.2 & & 15.5 & \\
\hline No. of stressors in previous $12 \mathrm{mo}$ & & & $<0.001$ & & $<0.001$ \\
\hline 0 & 554 & 4.2 & & 5.7 & \\
\hline 1 & 251 & 7.3 & & 8.8 & \\
\hline$\geqslant 2$ & 183 & 18.5 & & 24.1 & \\
\hline Directly witnessed the events & & & 0.01 & & 0.46 \\
\hline No & 611 & 5.5 & & 9.2 & \\
\hline Yes & 370 & 10.4 & & 10.8 & \\
\hline $\begin{array}{l}\text { Symptoms of a panic attack during } \\
\text { or soon after the events }\end{array}$ & & & $<0.001$ & & $<0.001$ \\
\hline No & 864 & 4.0 & & 7.6 & \\
\hline Yes & 124 & 31.5 & & 24.6 & \\
\hline Friend or relative killed & & & 0.18 & & 0.04 \\
\hline No & 880 & 7.0 & & 8.7 & \\
\hline Yes & 108 & 11.3 & & 17.8 & \\
\hline Lost possessions & & & 0.01 & & 0.70 \\
\hline No & 949 & 6.6 & & 9.6 & \\
\hline Yes & 36 & 28.4 & & 11.9 & \\
\hline Involved in rescue effort & & & 0.03 & & 0.25 \\
\hline No & 877 & 6.4 & & 9.2 & \\
\hline Yes & 111 & 16.2 & & 14.1 & \\
\hline Lost job because of attacks & & & 0.005 & & 0.006 \\
\hline No & 924 & 6.2 & & 8.5 & \\
\hline Yes & 64 & 25.9 & & 28.6 & \\
\hline
\end{tabular}

*Current PTSD or depression was defined as symptoms consistent with the diagnosis within 30 days before the interview. The sample was weighted to account for the number of adults and number of telephones in the household.

$\dagger$ Numbers may not add up to 988 because not all the respondents answered all the questions.

$\ddagger$ The chi-square test was used for comparisons; P values are two-tailed. 
had PTSD were sex $(\mathrm{P}=0.005)$, residence before the attacks $(\mathrm{P}=0.04)$, level of social support $(\mathrm{P}=0.01)$, number of stressors in the 12 months before September $11(\mathrm{P}<0.001)$, whether the respondent witnessed the events $(\mathrm{P}=0.01)$, whether the respondent had a panic attack during or soon after the events $(\mathrm{P}<0.001)$, whether possessions were lost $(\mathrm{P}=0.01)$, whether the respondent was involved in the rescue effort $(\mathrm{P}=0.03)$, and whether the respondent lost a job because of the attacks $(\mathrm{P}=0.005)$.

Covariates associated with whether the respondent had depression were sex $(\mathrm{P}=0.03)$, race or ethnic group $(\mathrm{P}=0.03)$, yearly household income $(\mathrm{P}=$ $0.006)$, level of education $(\mathrm{P}=0.007)$, level of social support $(\mathrm{P}<0.001)$, number of stressors in the 12 months before September $11(\mathrm{P}<0.001)$, whether the respondent had a panic attack during or soon after the events $(\mathrm{P}<0.001)$, whether a friend or relative died during the attacks $(\mathrm{P}=0.04)$, and whether the respondent lost a job because of the attacks $(\mathrm{P}=0.006)$.

\section{Multivariate Analyses}

In a multivariate logistic-regression model (Table 2), significant predictors of PTSD were Hispanic ethnicity as compared with white race (odds ratio, 2.6), two or more stressors in the 12 months before September 11 as compared with none (odds ratio, 5.5), a panic attack (odds ratio, 7.6), residence south of Canal Street before the attacks (odds ratio, 2.9), and loss of possessions due to the attacks (odds ratio, 5.6). The significant predictors of depression were Hispanic ethnicity (odds ratio, 3.2), two or more stressors in the 12 months before September 11 (odds ratio, 3.4), a panic attack (odds ratio, 2.6), a low as compared with a high level of social support (odds ratio, 2.4), the death of a friend or relative in the attacks (odds ratio, 2.3), and loss of a job because of the attacks (odds ratio, 2.8).

\section{DISCUSSION}

In our survey of a representative sample of adults living south of 110th Street in Manhattan, conducted five to eight weeks after the September 11 attacks, 7.5 percent of the respondents reported symptoms consistent with the diagnosis of current PTSD, and 9.7 percent reported symptoms consistent with the diagnosis of current depression. These prevalences suggest that in the area below 110th Street approximately 67,000 persons had PTSD and approximately 87,000 had depression during the time of the study. ${ }^{9}$ Although the estimated prevalences of current psychopathology vary according to the population studied, in a benchmark national study, the prevalence of PTSD within the previous year was 3.6 percent, ${ }^{10}$ and the prevalence of depression within the previous 30

Table 2. Multivariate Associations between Characteristics of the Respondents and Current Post-Traumatic Stress Disorder (PTSD) Or Depression. *

VARIABLE

Race or ethnic group

White

Black

Asian

Hispanic

Other

No. of stressors in previous $12 \mathrm{mo}$ 0

1

$\geqslant 2$

Symptoms of a panic attack during or soon after the events

No

Yes

Residence before September 11

Between 110th St. and Canal St.

South of Canal Street

Lost possessions

No

Yes

Social support in previous $6 \mathrm{mo}$

High

Medium

Low

Friend

No

Lost job because of attacks

No

*Current PTSD or depression was defined as symptoms consistent with the diagnosis within 30 days before the interview.

†CI denotes confidence interval.

days was 4.9 percent, ${ }^{11}$ suggesting that the prevalences in our survey were approximately twice the baseline values.

The prevalence of psychological sequelae of disasters has been documented in only a few communitybased samples, and comparison of the findings is limited by differences in sampling frames and the interval between the event and the assessment. Using outcome measures that were similar to ours, Hanson et al. reported that the overall prevalence of PTSD was 4.1 percent six months after the 1992 civil disturbances in Los Angeles County.12 The prevalence of depression in our study is similar to that reported after floods ( 9.5 percent). ${ }^{13}$

Persons directly affected by disasters have higher rates of post-event psychiatric disorders than persons indirectly affected. ${ }^{14,15}$ Our survey showed that the prevalence of PTSD was higher among the persons who were most directly exposed to the attacks or their 
consequences (e.g., those living south of Canal Street, the area closest to the attacks, and those who lost possessions) than among persons with less direct exposure. Factors associated with grief (e.g., loss of a family member) increased the likelihood of depression, a finding that is consistent with the results of previous studies. ${ }^{16,17}$

We found bivariate associations between female sex and both PTSD and depression, a finding that is consistent with the results of most studies. ${ }^{3,16,18}$ However, our adjusted models suggested that other factors may have been important mediators of the association between sex and psychopathology after this disaster. For example, the level of social support may have influenced the association between sex and depression.

Hispanic ethnicity was associated with both PTSD and depression, and the association was independent of other covariates. Although the relation between membership in a minority group and psychopathology after a disaster has been suggested in previous studies, ${ }^{19}$ few have specifically examined the role of Hispanic ethnicity. ${ }^{20}$ Research with veterans of the Vietnam War has shown that Hispanics may have a higher prevalence of PTSD than persons of other racial or ethnic backgrounds. ${ }^{21}$ Sociocultural influences have been proposed as mediators of this relation. ${ }^{22}$

We also found a relation between a low level of social support and both PTSD and depression in bivariate analyses and between a low level of social support and depression in adjusted analyses. Social ties have a positive role in mental health. ${ }^{23}$ After a disaster, a low level of social support has been shown to be related to PTSD and depressive symptoms. ${ }^{24,25}$

Our study provides strong evidence of an association between initial panic symptoms and subsequent psychopathology. Although the prognostic role of panic symptoms in determining the risk of PTSD or depression cannot be determined from a cross-sectional survey, this finding is consistent with previous research documenting associations between initial emotional responses to trauma and the development of PTSD. ${ }^{26,27}$ These findings suggest that interventions addressing such initial reactions to a disaster may help prevent the development of long-lasting psychological sequelae. ${ }^{28}$

Prospective evaluations of PTSD in trauma victims and in the general population suggest that the symptoms of PTSD decrease substantially within three months after a traumatic experience ${ }^{29}$ but that up to a third of cases of PTSD may not fully remit. 3,30 How long the psychological sequelae of the September 11 attacks will last remains to be seen, and it is possible that the prevalence of symptoms in our study reflects transient stress reactions to some degree. However, the ongoing threat of terrorist attacks may affect both the severity and the duration of these psychological symptoms. ${ }^{31}$ More than 100,000 persons in New York City may lose their jobs as a result of the September 11 attacks, ${ }^{32}$ and the cleanup efforts and disruption of services throughout the city will continue for a long time. In this context, the high prevalence of psychopathology that we documented among the residents of Manhattan is not surprising. Future research in New York City should determine the prognostic role of the factors that were associated with PTSD and depression in our study.

Supported by grants from the United Way of New York City, the New York Community Trust, and the National Institute on Drug Abuse (R01 DA14219-01S1).

We are indebted to Mr. Mark Morgan for invaluable contributions to the conduct of this study; to Dr. Joseph Boscarino for ongoing feedback; to Dr. Donald Hoover for statistical assistance; to Dr. Neal Cohen, Commissioner of Health for the New York City Department of Health, and Mr. Len McNally of the New York Community Trust, for their encouragement; to the interviewers at Schulman, Ronca, and Bucuvalas; and to all the persons who participated in the study during a difficult time for New Yorkers.

\section{REFERENCES}

1. Dead and missing. New York Times. December 26, 2001:B2. 2. Rubonis AV, Bickman L. Psychological impairment in the wake of disaster: the disaster-psychopathology relationship. Psychol Bull 1991;109: 384-99.

3. Kessler RC, Sonnega A, Bromet E, Hughes M, Nelson CB. Posttraumatic stress disorder in the National Comorbidity Survey. Arch Gen Psychiatry 1995;52:1048-60.

4. Kilpatrick DG, Saunders BE, Veronen LJ, Best CL, Von JM. Criminal victimization: lifetime prevalence, reporting to police, and psychological impact. Crime Delinquency 1987;33:479-89.

5. Resnick HS, Kilpatrick DG, Dansky BS, Saunders BE, Best CL. Prevalence of civilian trauma and posttraumatic stress disorder in a representative national survey of women. J Consult Clin Psychol 1993;61:984-91.

6. Sherbourne CD, Stewart AL. The MOS social support survey. Soc Sci Med 1991;32:705-14

7. Diagnostic and statistical manual of mental disorders, 4th ed.: DSM-IV. Washington, D.C.: American Psychiatric Association, 1994.

8. Shah B, Barnwell B, Bieler G. SUDAAN user's manual, release 7.5. Research Triangle Park, N.C.: Research Triangle Institute, 1997.

9. Bureau of the Census. Census summary tape, file 3A (STF3A). Washington, D.C.: Department of Commerce, 2000 (data file).

10. Department of Health and Human Services. Mental health: a report of the Surgeon General. Rockville, Md.: Substance Abuse and Mental

Health Services Administration, Center for Mental Health Services, National Institute of Mental Health, 1999. (Also available at http:// www.surgeongeneral.gov/Library/MentalHealth/pdfs/front.pdf.)

11. Blazer DG, Kessler RC, McGonagle KA, Swartz MS. The prevalence and distribution of major depression in a national community sample: the National Comorbidity Survey. Am J Psychiatry 1994;151:979-86.

12. Hanson RF, Kilpatrick DG, Freedy JR, Saunders BE. Los Angeles County after the 1992 civil disturbances: degree of exposure and impact on mental health. J Consult Clin Psychol 1995;63:987-96.

13. Ginexi EM, Weihs K, Simmens SJ, Hoyt DR. Natural disaster and depression: a prospective investigation of reactions to the 1993 Midwest floods. Am J Community Psychol 2000;28:495-518.

14. North CS, Nixon SJ, Shariat S, et al. Psychiatric disorders among survivors of the Oklahoma City bombing. JAMA 1999;282:755-62.

15. Green B, Grace M, Lindy J, Gleser GC, Leonard AC, Kramer TL. Buffalo Creek survivors in the second decade: comparison with unexposed and nonlitigant groups. J Appl Soc Psychol 1990;20:1033-50.

16. Goenjian AK, Molina L, Steinberg AM, et al. Posttraumatic stress and depressive reactions among Nicaraguan adolescents after hurricane Mitch. Am J Psychiatry 2001;158:788-94.

17. Mazure CM, Bruce ML, Maciejewski PK, Jacobs SC. Adverse life events and cognitive-personality characteristics in the prediction of major 
depression and antidepressant response. Am J Psychiatry 2000;157:896903.

18. Shore JH, Vollmer WM, Tatum EL. Community patterns of posttraumatic stress disorders. J Nerv Ment Dis 1989;177:681-5.

19. Pole N, Best SR, Weiss DS, et al. Effects of gender and ethnicity on duty-related posttraumatic stress symptoms among urban police officers. J Nerv Ment Dis 2001;189:442-8.

20. Fothergill A, Maestas EGM, Darlington JD. Race, ethnicity and disasters in the United States: a review of the literature. Disasters 1999;23: 156-73.

21. Ortega $A N$, Rosenheck R. Posttraumatic stress disorder among Hispanic Vietnam veterans. Am J Psychiatry 2000;157:615-9.

22. Ruef AM, Litz BT, Schlenger WE. Hispanic ethnicity and risk for combat-related posttraumatic stress disorder. Cultur Divers Ethni Minor Psychol 2000;6:235-51.

23. Kawachi I, Berkman LF. Social ties and mental health. J Urban Health 2001;78:458-67.

24. Madakasira $S$, O'Brien KF. Acute posttraumatic stress disorder in victims of a natural disaster. J Nerv Ment Dis 1987; 175:286-90.

25. Fullerton CS, Ursano RJ, Kao TC, Bharitya VR. Disaster-related be reavement: acute symptoms and subsequent depression. Aviat Space Environ Med 1999;70:902-9.
26. Harvey AG, Bryant RA. The relationship between acute stress disorder and posttraumatic stress disorder: a 2 -year prospective evaluation. J Consult Clin Psychol 1999;67:985-8.

27. Tucker P, Pfefferbaum B, Nixon SJ, Dickson W. Predictors of posttraumatic stress symptoms in Oklahoma City: exposure, social support, peri-traumatic responses. J Behav Health Serv Res 2000;27:406-16.

28. Resnick H, Acierno R, Holmes M, Kilpatrick DG, Jager N. Prevention of post-rape psychopathology: preliminary findings of a controlled acute rape treatment study. J Anxiety Disord 1999;13:359-70.

29. Shalev AY, Freedman S, Peri T, et al. Prospective study of posttraumatic stress disorder and depression following trauma. Am J Psychiatry 1998; 155:630-7.

30. Rothbaum BO, Foa EB, Riggs DS, Murdock T, Walsh W. A prospec tive examination of posttraumatic stress disorder in rape victims. J Traumatic Stress 1992;5:455-75.

31. Shalev AY. Measuring outcome in posttraumatic stress disorder. J Clin Psychiatry 2000;61:Suppl 5:33-9.

32. Eaton L. Loss of 79,000 jobs adds to city's economic woes. New York Times. November 16, 2001:Al.

Copyright () 2002 Massachusetts Medical Society. 